\title{
Long-term results of endoclamping in patients undergoing minimally invasive mitral valve surgery where external aortic clamping cannot be used - a propensity matched analysis
}

Ayse Cetinkaya ${ }^{1 *}$, Emad Ebraheem ${ }^{1}$, Karin Bramlage ${ }^{2}$, Stefan Hein ${ }^{1}$, Peter Bramlage ${ }^{2} \mathbb{B}$, Yeong-Hoon Choi ${ }^{1}$, Markus Schönburg ${ }^{1}$ and Manfred Richter ${ }^{1}$

\begin{abstract}
Background: Minimally invasive mitral valve surgery is standard of care in many centres and it is commonly associated with the need for cardiopulmonary bypass. Conventional external aortic clamping (exoclamping) is not always feasible, so endoaortic clamping (endoclamping) has evolved as a viable alternative. The aim of this study is to compare endoclamping (Intraclude ${ }^{T M}$, Edwards Lifesciences) with exoclamping (Chitwood) during minimally invasive mitral valve procedures.

Methods: This single-centre study included 822 consecutive patients undergoing minimally invasive mitral valve procedures. The endoclamp was used in 64 patients and the exoclamp in 758. Propensity-score (PS) matching was performed resulting in 63 patients per group. Outcome measures included procedural variables, length of intensive care unit (ICU) and hospital stay, major adverse cardiac and cerebrovascular events (MACCE) and repeat surgery.

Results: The mean age was similar in the two group (62.2 [endoclamp] vs. 63.5 [exoclamp] years; $p=0.554$ ), as were the cardiopulmonary bypass (145 vs. $156 \mathrm{~min} ; p=0.707$ ) and the procedure time (203 vs. $211 \mathrm{~min} ; p=0.648$ ). The X-clamp time was significantly shorter in the endoclamp group ( $88 \mathrm{vs.} 99 \mathrm{~min} ; p=0.042$ ). Length of ICU stay ( 25.0 vs. $23.0 \mathrm{~h}$ ) and length of hospital stay (10.0 vs. 9.0 days) were slightly longer in the endoclamp group, but without statistical significance. There were nominal but no statistically significant differences between the groups in the rates of stroke, vascular complications, myocardial infarction or repeat mitral valve surgery. The conversion rate to open sternotomy approach was $2.4 \%$ without difference between groups. The estimated 7-year survival rate was similar for both groups (89.9\% [endoclamp]; 84.0\% [exoclamp]) with a hazard ratio of 1.291 (95\% Cl 0.453-3.680).
\end{abstract}

Conclusions: Endoaortic clamping is an appropriate and reasonably safe alternative to the conventional Chitwood exoclamp for patients in which the exoclamp cannot be used because the ascending aorta cannot be safely mobilised.

Keywords: Mitral valve repair, Endoaortic clamping, Aortic clamping

\footnotetext{
* Correspondence: a.cetinkaya@kerckhoff-klinik.de

1 Department of Cardiac Surgery, Kerckhoff-Heart Center Bad Nauheim,

Campus of the University Hospital Giessen, Benekestraße 2-8, 61231 Bad Nauheim, Germany

Full list of author information is available at the end of the article
}

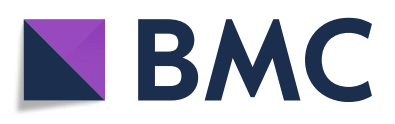

( ) The Author(s). 2020 Open Access This article is licensed under a Creative Commons Attribution 4.0 International License, which permits use, sharing, adaptation, distribution and reproduction in any medium or format, as long as you give appropriate credit to the original author(s) and the source, provide a link to the Creative Commons licence, and indicate if changes were made. The images or other third party material in this article are included in the article's Creative Commons licence, unless indicated otherwise in a credit line to the material. If material is not included in the article's Creative Commons licence and your intended use is not permitted by statutory regulation or exceeds the permitted use, you will need to obtain permission directly from the copyright holder. To view a copy of this licence, visit http://creativecommons.org/licenses/by/4.0/. The Creative Commons Public Domain Dedication waiver (http://creativecommons.org/publicdomain/zero/1.0/) applies to the data made available in this article, unless otherwise stated in a credit line to the data. 


\section{Background}

Minimally invasive mitral valve surgery (MIMVS) is becoming the standard-of-care in suitable cases in many centres. It is commonly associated with the need for cardiopulmonary bypass, but conventional external aortic clamping ('exoclamping') is not always feasible or desirable. In this setting, endoaortic clamping ('endoclamping') has evolved into a viable alternative for providing aortic cross-clamping, antegrade cardioplegia and aortic root venting. In addition, a pressure lumen allows monitoring of the aortic root pressure.

Rates of endo- versus exoclamping in this setting range from $5 \%$ at our institution, to over $23 \%$ reported by Ius et al. [1], and up to $42 \%$ reported by Murzi et al. [2] Endoclamping has been associated with less fibrillatory arrest than exoclamping, with no prolongation of clamp time or pump time, and similar in-hospital, as well as late, outcomes [3]. On the other hand, aortic dissections with conversion to sternotomy, problems exposing the aorta and instability of the endoclamp have been reported as complications associated with the endoclamp procedure [1, 4]. Finally, costs for the endoclamp are higher than for the standard exoclamp.

Common practice at our institution is to clamp the ascending aorta directly with a flexible transthoracic clamp if the aorta can be safely dissected and clamped and to deliver antegrade cold crystalloid cardioplegia. In cases where the ascending aorta cannot be safely mobilised, we use endoclamping with antegrade cardioplegia. To date, we have successfully used the endoclamping device in a total of 64 patients undergoing MIMVS at our institution. To explore the relative merits of endoclamping in those who cannot undergo exoclamping in the MIMV $\mathrm{S}$ setting, we conducted an analysis of patients treated via MIMVS at our centre in which we matched those undergoing exoclamping to those undergoing endoclamping using propensity scoring.

\section{Materials and methods}

This study was a single-centre, retrospective analysis of mitral valves surgeries performed at the Kerckhoff-Heart Center Bad Nauheim, Germany [5]. The study included patients undergoing MIMVS within the time period 2009-2015, involving either aortic endoclamping (Intraclude $^{\mathrm{rs}}$, Edwards Lifesciences) or conventional aortic exoclamping. Interventions were performed by a group of five surgeons with no imbalance by approach. The study complied with the Declaration of Helsinki and its amendments. The study was assessed by the site's ethical committee (University of Giessen, Germany) which stated that no approval and no patient informed consent was necessary because of its retrospective nature and the use of anonymised data.
Patient and public involvement

Neither patients nor the public were involved in this analysis.

\section{Data, outcomes and definitions}

For patients who had undergone a mitral valve procedure, all electronic medical records (including inpatient and outpatient notes and the results of any diagnostic testing) were reviewed. Clinical variables, including patient age, sex, comorbid diseases, prior cardiology procedures, echocardiographic procedures and other pertinent medical/surgical history, were recorded. Follow-up data concerning complications and echocardiography parameters were collected at the patient's last follow-up hospital visit.

\section{Statistics}

Data were analysed using descriptive statistics, with categorical variables presented as mean values with standard deviation or as frequencies (\%), and continuous variables presented as the median and interquartile range (IQR).

Propensity score matching was performed. The propensity score for each patient was calculated by logistic regression with adjustment for 6 key baseline variables (hypertension, diabetes, coronary artery disease, prior myocardial infarction within 90 days, prior aortic valve implantation and emergency indication). When matching patients $1: 1$ a difference in propensity score of $0.01 \%$ (0.0001) was tolerated.

Comparisons between the endocamp and exoclamp groups were carried out using t-test or Mann-Whitney $\mathrm{U}$ test for continuous variables and a Fisher's exact or Chi-square test for categorical variables. Survival analyses were presented as Kaplan-Meier curves. Hazard ratios (HRs) were calculated by Cox regression. In all cases, a two-tailed $p$-value of $<0.05$ was considered statistically significant. All statistical tests were performed using IBM SPSS Statistics software version 24.0 (IBM Corporation, Armonk, New York, USA).

\section{Results}

Among 822 consecutive MIMVS procedures performed at our centre between 2009 and 2015, the endoclamp was used in 64 patients and the exoclamp in 758 patients (Fig. 1). Propensity score matching resulted in 63 patients per group.

\section{Patient characteristics}

In the overall (unmatched) population, patients had a mean age of 63 years and $42.3 \%$ were female. Patients tended to be highly symptomatic, with $68.5 \%$ being in New York Heart Association (NYHA) class III/IV (Table 1). Comorbidities were common, including 


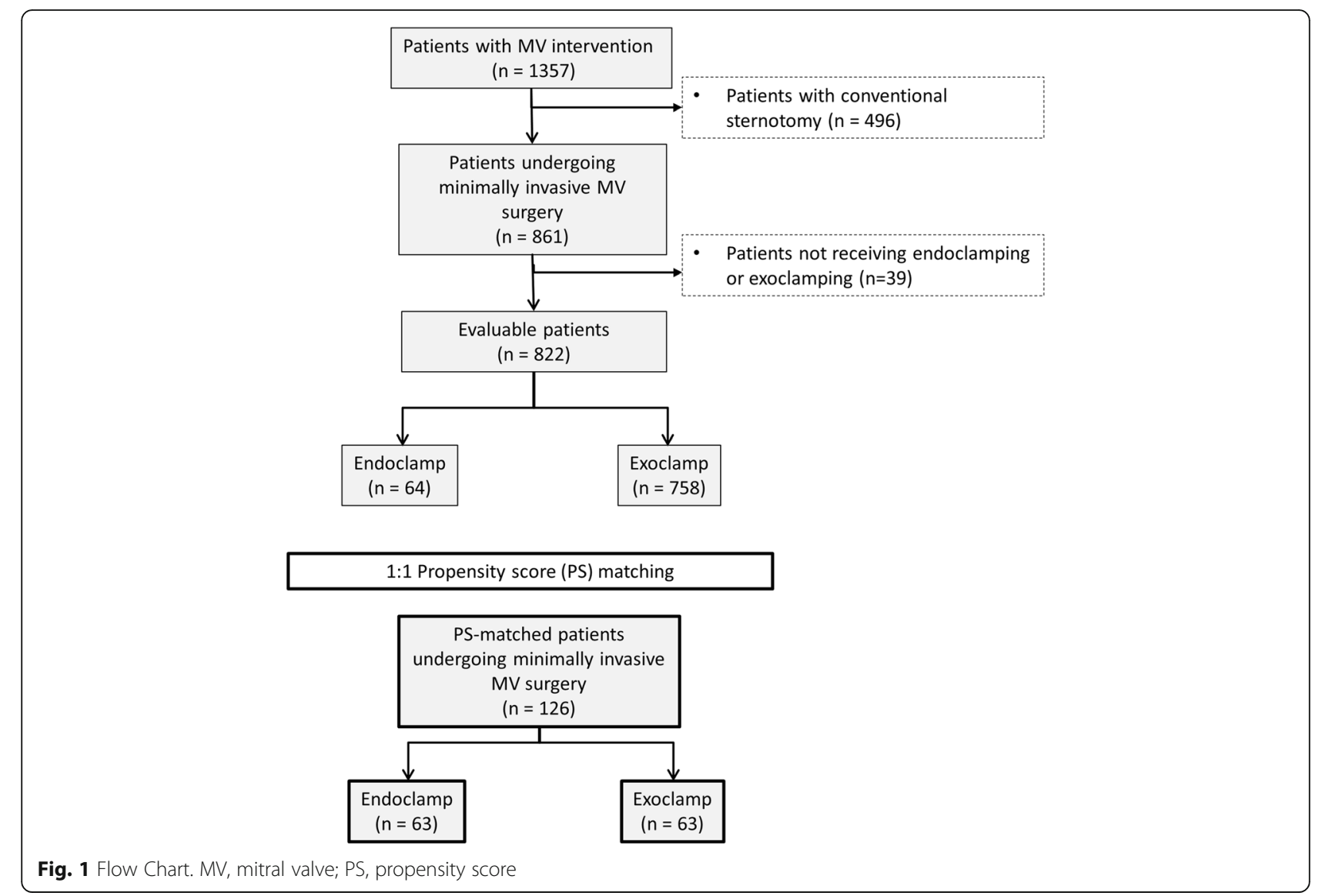

atrial fibrillation (31.5\%) and pulmonary hypertension (14.0\%). There were a few differences between the groups in the unmatched population; however, PSmatching resulted in two similar groups of patients without any significant differences in baseline characteristics (Table 1). In the PS-matched cohort, the mean age was 62.2 years in the endoclamp group and 63.5 years in the exoclamp group $(p=0.554)$. The two groups were generally similar in terms of mitral valve pathology and other echocardiographic parameters (Table 2).

\section{Procedural details and outcomes}

There were several differences between the groups with respect to the procedures that were performed. Anterior mitral valve leaflet reconstruction $(74.6 \%$ vs. $19.0 \%$; $p<$ $0.001)$ and the use of loops $(95.2 \%$ vs. $63.5 \% ; p<0.001)$ were significantly more common in the exoclamp group than the endoclamp group, whereas posterior mitral valve leaflet reconstruction was more common in the endoclamp group $(76.2 \%$ vs. $55.6 \% ; p=0.015)$. Among concomitant procedures, left atrial appendage closure $(33.3 \%$ vs. $1.6 \% ; p<0.001)$ and patent foramen ovale closure $(22.2 \%$ vs. $1.6 \% ; p<0.001)$ were more common in the exoclamp group.
The median cardiopulmonary bypass time was similar in the endoclamp and exoclamp groups (145 vs. 156 min; $p=0.707$ ), as was the median total procedure time (203 vs. $211 \mathrm{~min} ; p=0.648$ ); Table 3 . However, the median X-clamp time was significantly shorter in the endoclamp group (88 vs. $99 \mathrm{~min} ; p=0.042$ ). Median length of ICU stay $(25.0$ vs. $23.0 \mathrm{~h})$ and length of hospital stay (10.0 vs. 9.0 days) were slightly longer for patients in the endoclamp group than in the exoclamp group, but these differences did not achieve statistical significance.

The conversion rate to open sternotomy approach was $2.4 \%$ and did not differ between groups $(p=1.000)$ (Table 3).There were no significant differences in the rate of procedure-related complications between the two groups (Table 4). The most common complication in both groups was atrial fibrillation $(11.1 \%$ in the endoclamp group vs. $17.5 \%$ in the exoclamp group; $p=$ 0.446). There were no deaths in the immediate $(72-\mathrm{h})$ post-procedural period in either group.

\section{Functional outcomes}

There were no significant differences in the median [IQR] mitral valve gradient between the endoclamp and exoclamp groups post-surgery (Fig. 2a). 
Table 1 Patient characteristics

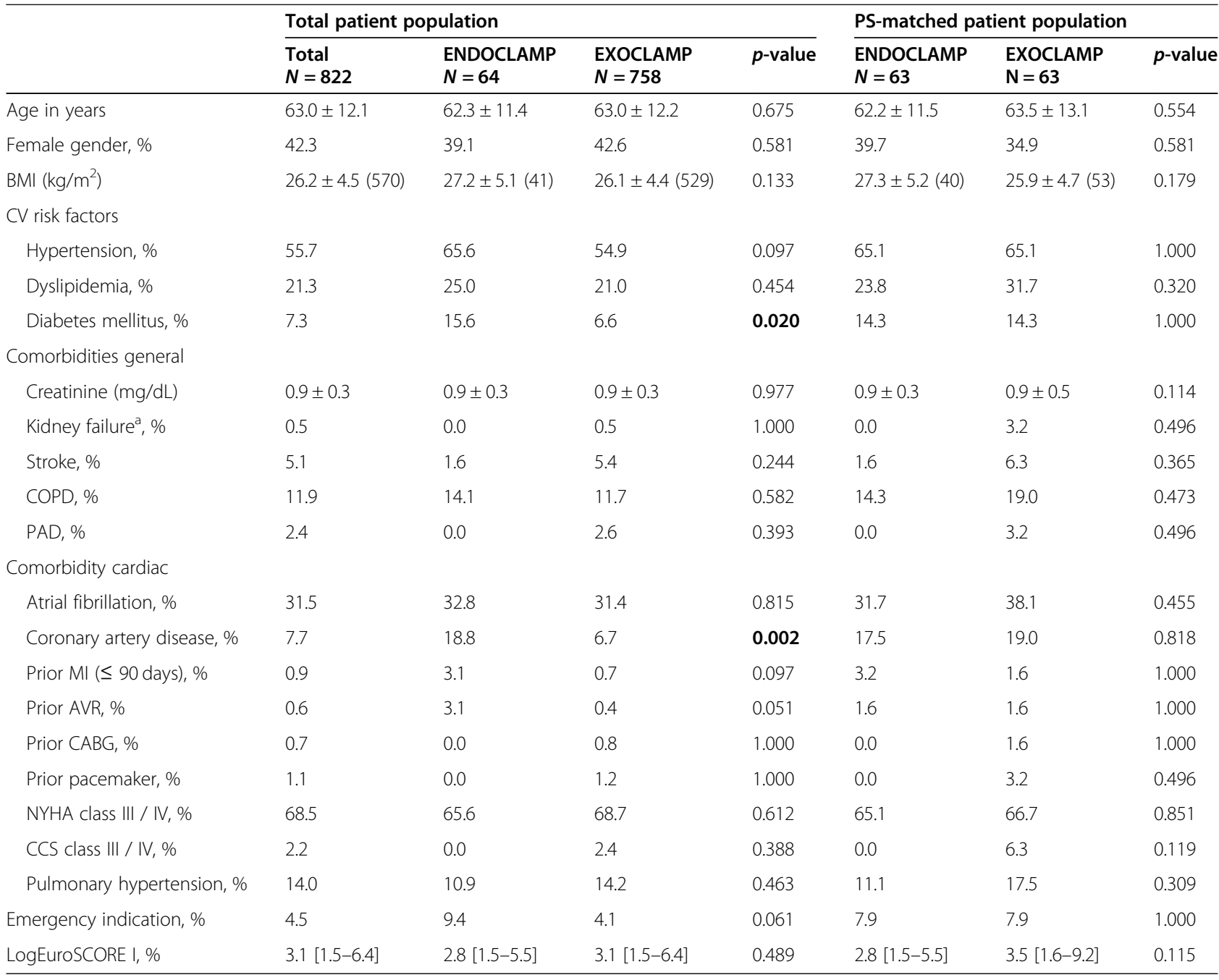

Legend: values are reported as percent or mean \pm SD; AVR Aortic valve replacement, $B M I$ Body mass index, CABG Coronary artery bypass graft, CCS Canadian Cardiovascular society, COPD Chronic obstructive pulmonary disease, CV Cardiovascular, MI Myocardial infarction, NYHA New York Heart Association, PAD Peripheral artery disease, SD Standard deviation; ${ }^{a}$ Creatinine $>2.26 \mathrm{mg} / \mathrm{dL}$

Before surgery, there was no between-group difference in the severity of mitral insufficiency. Long-term mitral valve competency was good in both groups. However, there was trend towards a better outcome (in terms of severity of mitral insufficiency) in the endoclamp group, which achieved statistical significance during long-term follow-up (Fig. 2b).

\section{Clinical follow up}

There were no statistically significant differences between the groups in the rates of death, stroke, vascular complications, myocardial infarction, pacemaker implantation or repeat mitral valve surgery at day 30 postprocedure (Table 5). However, event rates were low and potential differences in vascular complications and stroke may have been affected by the sample size. There were 2 deaths among the 63 patients in the endoclamp group (3.2\%) compared with 4/63 (6.3\%) in the exoclamp group $(p=0.680)$. Stroke occurred in $6 / 63(9.5 \%)$ patients in the endoclamp group compared with $1 / 63$ (1.6\%) in the exoclamp group $(p=0.115)$.

The estimated 7-year survival rate was similar for both groups $(89.9 \%$ with endoclamp and $84.0 \%$ with exoclamp), with an HR of 1.291 (95\% CI 0.453-3.680); Fig. 3.

\section{Discussion}

Two different techniques for aortic occlusion can be used during minimally invasive cardiac surgery - external (transthoracic) aortic clamping or endoaortic balloon occlusion. Data on the use of these aortic occlusion techniques comes mainly from retrospective observational studies, and few direct comparisons have been reported [6]. We performed a PS-matched analysis of 
Table $2 \mathrm{MV}$ pathology and echocardiographic parameters

\begin{tabular}{|c|c|c|c|}
\hline & $\begin{array}{l}\text { ENDOCLAMP } \\
(\mathrm{N}=63)\end{array}$ & $\begin{array}{l}\text { EXOCLAMP } \\
(\mathrm{N}=63)\end{array}$ & $p$-value \\
\hline \multicolumn{4}{|c|}{ Echocardiographic parameters } \\
\hline LVEF, \% & $57.8 \pm 9.3$ & $58.7 \pm 10.1$ & 0.607 \\
\hline LVEDD (mm) & $55.2 \pm 6.5$ & $57.1 \pm 12.3$ & 0.293 \\
\hline LVESD (mm) & $35.9 \pm 6.8$ & $35.3 \pm 8.5$ & 0.702 \\
\hline \multicolumn{4}{|l|}{ MV pathologies } \\
\hline Degenerative, \% & 98.4 & 100 & 1.000 \\
\hline Functional, \% & 1.6 & 0 & 1.000 \\
\hline Acute endocarditis, \% & 6.3 & 1.6 & 0.365 \\
\hline Annulus dilatation, \% & 90.5 & 100 & 0.028 \\
\hline Annulus calcification, \% & 4.8 & 7.9 & 0.717 \\
\hline MV stenosis, \% & 3.2 & 3.2 & 1.000 \\
\hline $\mathrm{MVI} \geq$ grade $\|, \%$ & 100 & 96.8 & 0.496 \\
\hline
\end{tabular}

Legend: values are reported as percent or mean $\pm S D ; A M L$ Anterior mitral valve leaflet, $L V E D D$ Left ventricular end-diastolic pressure, $L V E F$ Left ventricular ejection fraction, LVESD Left ventricular end-systolic pressure, MV Mitral valve, MVI Mitral valve insufficiency, SD Standard deviation

patients undergoing MIMVS at our centre to describe the outcomes of endoclamping in patients where exoclamping could not be used. Key findings included high primary MV reconstruction rates and good long-term MV competency in both groups; no significant betweengroup differences in complication rates or survival, which may need to be interpreted with caution because of the low absolute number with events; and shorter Xclamp and total procedure times with endoclamping.

At our institution, transthoracic clamping is more commonly performed, provided the aorta can be safely dissected and clamped; endoclamping is used in cases where the ascending aorta cannot be safely mobilised. A similar approach is used at other centres [2]. An endoclamp may also be preferred for re-operative procedures, where scarring around the aortic root can make it difficult to apply an external clamp [7-9]. There is a learning curve for the technique associated with using an endoaortic balloon, with outcomes generally improving as the number of completed procedures increases [10]. However, with good patient selection, a highly competent team, use of an appropriate insertion technique and imaging, and careful monitoring, the risk of adverse outcomes can be minimised $[8,11]$.

We compared outcomes after endoclamping and exoclamping using PS-matched groups to take account of baseline characteristics. We found some differences between the PS-matched groups in terms of the specific procedures that were performed: anterior mitral valve leaflet reconstruction, left atrial appendage closure and patent foramen ovale closure were all more common in the exoclamp group, whereas posterior mitral valve leaflet reconstruction was more common in the endoclamp group.
The reasons for this difference are not clear, but it is possible that surgeons did not consider the endoclamp procedure to be appropriate in some patients undergoing more complex procedures. Other studies have not reported differences in the type of operation performed between endoclamp and exoclamp groups [12,13].

Our analysis found no significant difference in the overall procedure time or in cardiopulmonary bypass time between the two groups, but the median X-clamp time was shorter (by $11 \mathrm{~min}$ ) in the endoclamp group. Some previous studies have found no significant difference in cardiopulmonary bypass and X-clamp times between exoclamping and endoclamping groups [12-15], whereas others have reported longer operating, cardiopulmonary bypass and X-clamp times with endoclamping $[7,16,17]$. Meta-analyses have generally found no significant difference in X-clamp or cardiopulmonary bypass times between endoclamping and exoclamping [6, $18,19]$. However, a subgroup analysis found some differences depending on the cannulation used for endoclamping: X-clamp and cardiopulmonary bypass times were shorter with exoclamping compared with endoclamping with femoral cannulation; however, X-clamp time was shorter with endoclamping with aortic cannulation compared with exoclamping, and cardiopulmonary bypass time did not differ between exoclamping and endoclamping with aortic cannulation [19].

In our study, ICU and hospital stays were slightly longer in the endoclamp group than the exoclamp group (by 2 and 1 days, respectively), but the differences were not statistically significant. This is consistent with most previous studies which have found no significant difference in the length of ICU stay [13-15] or hospital stay $[6,7,14,15,17]$, although one study reported a significantly longer hospital stay (by 2 days) after endoclamping [16] and another a significantly longer hospital stay (by 1 day) after exoclamping [13].

Successful primary mitral valve reconstruction rates were high and long-term mitral valve competency was good in both groups in our study. However, there was trend towards a better outcome with respect to valve competency in the endoclamp group, which achieved statistical significance during long-term follow-up. This is a somewhat surprising finding. Other studies have found no significant difference in the severity of mitral insufficiency between endoclamp and exoclamp groups at the time of discharge from hospital [7, 13, 15], but comparative data for this parameter after long-term follow-up are scarce.

We found no significant difference in the rates of periprocedural complications or adverse outcomes at 30 days post-procedure between the two groups. However, 30day event rates were low, which precludes meaningful $p$ values for the comparison at this timepoint. The rate of 
Table 3 Procedural details

\begin{tabular}{|c|c|c|c|}
\hline & $\begin{array}{l}\text { ENDOCLAMP } \\
(\mathrm{N}=63)\end{array}$ & $\begin{array}{l}\text { EXOCLAMP } \\
(\mathrm{N}=63)\end{array}$ & $p$-value \\
\hline \multicolumn{4}{|l|}{ Mitral valve repair } \\
\hline AML reconstruction & 19.0 & 74.6 & $<0.001$ \\
\hline PML reconstruction & 76.2 & 55.6 & 0.015 \\
\hline Annuloplasty ring & 90.5 & 96.8 & 0.273 \\
\hline Resection & 6.3 & 0 & 0.119 \\
\hline Loops & 63.5 & 95.2 & $<0.001$ \\
\hline Cleft Plicature & 31.7 & 28.6 & 0.698 \\
\hline Rate of successful repair ${ }^{a}$ & 88.9 & 88.9 & 1.000 \\
\hline \multicolumn{4}{|l|}{ Mitral valve replacement } \\
\hline Direct & 9.5 & 3.2 & 0.273 \\
\hline MV replacement after repair failure & 1.6 & 7.9 & 0.207 \\
\hline Biological & 7.9 & 6.3 & 1.000 \\
\hline Mechanical & 3.2 & 4.8 & \\
\hline \multicolumn{4}{|l|}{ Concomitant procedures } \\
\hline Cryoablation & 38.1 & 38.1 & 1.000 \\
\hline LAA closure & 1.6 & 33.3 & $<0.001$ \\
\hline Concomitant TVR & 4.8 & 7.9 & 0.717 \\
\hline PFO closure & 1.6 & 22.2 & $<0.001$ \\
\hline ASD closure & 0 & 0 & n.a. \\
\hline Myxom & 0 & 0 & n.a. \\
\hline \multicolumn{4}{|l|}{ Times } \\
\hline Procedure time (min) & $203.0[180.0-259.0]$ & $211.0[182.0-262.0]$ & 0.648 \\
\hline CPB time (min) & 145.0 [127.0-189.0] & 156.0 [122.0-182.0] & 0.707 \\
\hline X-clamp time (min) & 88.0 [76.0-109.0] & $99.0[80.0-124.0]$ & 0.042 \\
\hline Length of intubation (h) & $11.0[9.0-15.0]$ & $10.0[8.0-13.0]$ & 0.277 \\
\hline Length of ICU (h) & $25.0[21.0-76.0]$ & $23.0[21.0-48] 0$. & 0.246 \\
\hline Length of hospital stay (d) & $10.0[8.0-13.0]$ & $9.0[8.0-12.0]$ & 0.411 \\
\hline Conversion to sternotomy & 1.6 & 3.2 & 1.000 \\
\hline
\end{tabular}

Legend: values are reported as percent or median [IQR]; ${ }^{\text {a }}$ Three patients were excluded as they died within $72 \mathrm{~h}$ after the intervention (electromechanical decoupling $n=1$, low cardiac output and rhythm disturbances $\mathrm{n}=1$, cardiogenic shock and kidney failure $\mathrm{n}=1$ ); $A M L$ Anterior mitral valve leaflet, $A S D$ Atrial septal defect, CPB Cardiopulmonary bypass, ICU Intensive care unit, IQR Interquartile range, $L A A$ Left atrial appendage, $M V$ Mitral valve, $n . a$. Not applicable, $P F O$ Patent foramen ovale, $P M L$ Posterior mitral valve leaflet, SD Standard deviation, TVR Tricuspid valve reconstruction

all-cause mortality at 30 days was numerically slightly higher in the exoclamp group $(4 / 63 ; 6.3 \%)$ than in the endoclamp group $(2 / 63 ; 3.2 \%)$. Previous studies and meta-analyses have not found a significant difference in 30-day all-cause mortality rates between endoclamping and exoclamping groups $[6-8,12,13,18-20]$.

Strokes occurred in numerically more patients in the endoclamp group $(6 / 63 ; 9.5 \%)$ than in the exoclamp group $(1 / 63 ; 1.6 \%)$ in our study, but this was not statistically significant. While further investigation is needed to better understand why the occurrence of stroke was higher in patients in the endoclamp group in this analysis, previously published reports have suggested a possible increased risk of neurological complications with the use of endoaortic occlusion compared with external clamping [12, 21]. Conversely, other studies have not reported this finding [8]. Recent meta-analyses found no significant difference in the risk of cerebrovascular accidents between the two approaches $[18,19]$. Potential reasons for an increased stroke risk with endoclamping include the risk of emboli mobilisation by the guidewire, occlusion of arteries by balloon catheters that have migrated, and repositioning of balloons without partial deflation [18]. One meta-analysis found that the relative risk of neurological events with endoclamping versus exoclamping was lower in more recent publications than in older reports, and the authors suggested this may be due to the availability of improved devices and cannulas, greater surgeon experience 
Table 4 Procedure-related complications

\begin{tabular}{|c|c|c|c|}
\hline & $\begin{array}{l}\text { ENDOCLAMP } \\
(N=63)\end{array}$ & $\begin{array}{l}\text { EXOCLAMP } \\
(\mathrm{N}=63)\end{array}$ & $p$-value \\
\hline & $\%$ & $\%$ & \\
\hline Immediate $72 \mathrm{~h}$ procedural mortality & 0 & 0 & n.a. \\
\hline Wound infection & 0 & 0 & n.a. \\
\hline Vascular complication ${ }^{a}$ & 3.2 & 0 & 0.496 \\
\hline Pericardial tamponade & 1.6 & 1.6 & 1.000 \\
\hline AV block grade III & 3.2 & 4.8 & 1.000 \\
\hline Pneumonia & 3.2 & 3.2 & 1.000 \\
\hline Pneumothorax & 3.2 & 0.0 & 0.496 \\
\hline Pleural effusion & 1.6 & 1.6 & 1.000 \\
\hline Atrial Fibrillation & 11.1 & 17.5 & 0.446 \\
\hline
\end{tabular}

Legend: values are reported as percent; ${ }^{a}$ vascular complications mean complications in the groin (vascular occlusion or lymphatic fistula); AV Atrioventricular, $h$ Hours, MVI Mitral valve insufficiency, n.a. Not applicable

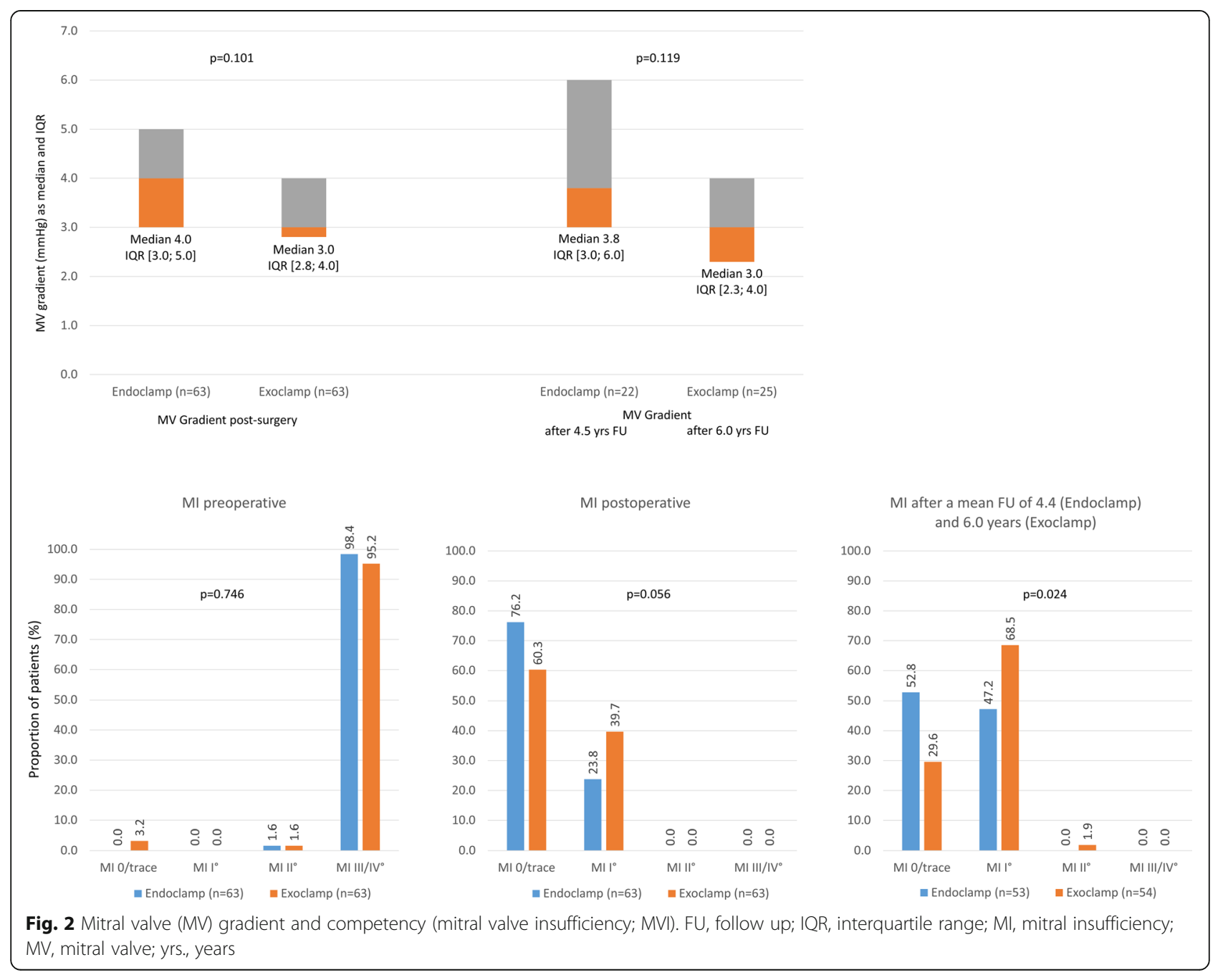


Table 5 30-day outcomes

\begin{tabular}{llll}
\hline & $\begin{array}{l}\text { ENDOCLAMP } \\
(\mathbf{N}=\mathbf{6 3})\end{array}$ & $\begin{array}{l}\text { EXOCLAMP } \\
(\mathbf{N}=\mathbf{6 3})\end{array}$ & $\boldsymbol{p}$-value \\
& $\%$ & $\%$ & \\
\hline Death & 3.2 & 6.3 & 0.680 \\
CV death & 3.2 & 1.6 & 1.000 \\
Non-CV death & 0 & 4.8 & 0.244 \\
Stroke & 9.5 & 1.6 & 0.115 \\
Acute renal failure & 6.3 & 3.2 & 0.680 \\
Myocardial infarction & 3.2 & 1.6 & 1.000 \\
Pacemaker implantation & 3.2 & 4.8 & 1.000 \\
Repeat MV surgery & 0 & 0 & n.a. \\
\hline
\end{tabular}

Legend: Values are reported as percentages; CV Cardiovascular, MV Mitral valve, n.a. Not applicable

and improved echocardiography guidance [18]. Despite this, the long-term (7-year) survival rates for patients were similar in both groups at our centre.

Endoaortic balloon occlusion is a versatile tool with applicability for a range of cardiac surgeries [22]. In general, certain measures are vital to ensure the safe performance of endoclamping. Viability should be confirmed using preoperative imaging [22]. Transoesophageal echocardiographic monitoring is vital to control guidewire advancement and ensure correct positioning of the endoclamp $[4,10,22]$. Changing the balloon position after the initial endoclamping has been undertaken is possible under echocardiographic surveillance and with partial deflation of the balloon to avoid damaging the aortic wall [22]. It has been shown that MIMVS using endoclamping is a safe procedure even during the initial learning curve
[11]. Our study confirms the feasibility and safety of endoclamping during MIMVS.

Some authors have suggested that endoclamping might be associated with higher costs than exoclamping at their centres, due to device costs, the technical complexity and a longer operative time [14, 15], whereas others have found that the endoclamping approach may be more economic [1]. However, no studies have reported specific cost data comparing the different approaches.

\section{Limitations}

The main limitation of this observational study is its retrospective nature, making it subject to potential selection bias. Propensity-score matching was used to mitigate this but did not eliminate it completely. For example, surgeon expertise, and the date at which surgery was performed during the 6-year study period, were not taken into account. The aim of the study was to report on the outcomes of patients receiving endoclamping during minimally invasive mitral surgery, but the use of propensityscore matching matched these patients to a control of patients receiving exoclamping to put the results into perspective. As a result, the data has become a comparison of endo- versus exoclamping rather than focusing on the outcomes of endoclamping alone. The relatively small number of patients in the endoclamp cohort meant that the study had a small overall sample size after propensity matching, and therefore lacked power to fully address some issues, such as whether there was a difference in the incidence of stroke. The final limitation of this study is that it was a single-centre study, which limits the generalisability of the results.

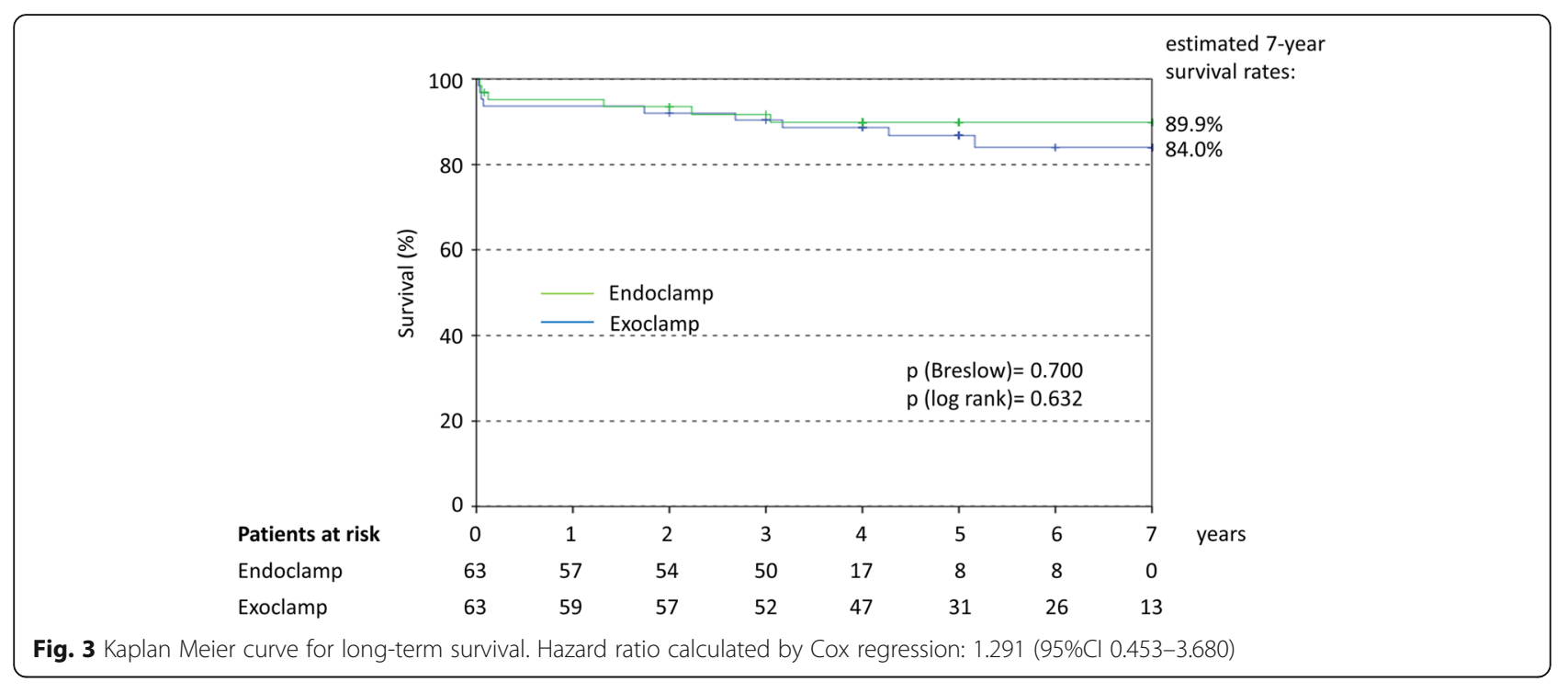


Additional studies, including randomized controlled trials and prospective observational studies with a larger sample size and adequate power are needed to address some issues further, such as the incidence of stroke with the endoclamp procedure. Such studies may also help to further define the subgroup of patients for whom endoaortic clamping is appropriate, and clarify the technical aspects of the procedure that are key for optimising patient outcomes.

\section{Conclusions}

Analysis of data from our centre indicates that endoaortic clamping (Intraclude ${ }^{\mathrm{m}}$, Edwards Lifesciences) is an appropriate and reasonably safe alternative to the conventional Chitwood exoclamp for patients in which the exoclamp cannot be used because the ascending aorta cannot be safely mobilised.

\section{Acknowledgements}

Not applicable.

\section{Authors' contributions}

$A C, E E, S H, M S$ and MR performed the surgery and collected the data. AC, $K B$, and $P B$ worked on the dataset, designed the analyses and developed the concept of the paper. $\mathrm{AC}$ and $\mathrm{PB}$ drafted the manuscript which was critically revised by $\mathrm{EE}, \mathrm{SH}, \mathrm{KB}, \mathrm{YHC}, \mathrm{MS}$, and $\mathrm{MR}$. The authors approved the final version of the manuscript.

\section{Funding}

Open Access funding enabled and organized by Projekt DEAL.

\section{Availability of data and materials}

Data are available from the corresponding author upon reasonable request.

\section{Ethics approval and consent to participate}

The study was assessed by the site's ethical committee (University of Giessen, Germany) which stated that no approval and no patient informed consent was necessary because of the retrospective nature and the use of anonymised data.

\section{Consent for publication}

Not applicable.

\section{Competing interests}

Peter Bramlage received research funding from Edwards Lifesciences unrelated to the present work. The other authors have no conflict of interest to disclose.

\section{Author details}

${ }^{1}$ Department of Cardiac Surgery, Kerckhoff-Heart Center Bad Nauheim, Campus of the University Hospital Giessen, Benekestraße 2-8, 61231 Bad Nauheim, Germany. ${ }^{2}$ Institute for Pharmacology and Preventive Medicine, Cloppenburg, Germany.

Received: 6 August 2020 Accepted: 5 October 2020

Published online: 14 October 2020

\section{References}

1. Ius F, Mazzaro E, Tursi V, Guzzi G, Spagna E, Vetrugno L, et al. Clinical results of minimally invasive mitral valve surgery: endoaortic clamp versus external aortic clamp techniques. Innovations (Phila). 2009;4(6):311-8.

2. Murzi M, Miceli A, Di Stefano G, Cerillo AG, Farneti P, Solinas M, et al. Minimally invasive right thoracotomy approach for mitral valve surgery in patients with previous sternotomy: a single institution experience with 173 patients. J Thorac Cardiovasc Surg. 2014;148(6):2763-8.
3. Glower DD, Desai B. Transaortic endoclamp for mitral valve operation through right minithoracotomy in 369 patients. Innovations (Phila). 2010; 5(6):394-9.

4. Falk V, Walther T, Diegeler A, Wendler R, Autschbach R, van Son JA, et al. Echocardiographic monitoring of minimally invasive mitral valve surgery using an endoaortic clamp. J Heart Valve Dis. 1996;5(6):630-7.

5. Cetinkaya A, Poggenpohl J, Bramlage K, Hein S, Doss M, Bramlage P, et al. Long-term outcome after mitral valve replacement using biological versus mechanical valves. J Cardiothorac Surg. 2019;14(1):120.

6. Khan H, Hadjittofi C, Uzzaman M, Salhiyyah K, Garg S, Butt S, et al. External aortic clamping versus endoaortic balloon occlusion in minimally invasive cardiac surgery: a systematic review and meta-analysis. Interact Cardiovasc Thorac Surg. 2018;27(2):208-14.

7. Mazine A, Pellerin M, Lebon JS, Dionne PO, Jeanmart H, Bouchard D. Minimally invasive mitral valve surgery: influence of aortic clamping technique on early outcomes. Ann Thorac Surg. 2013;96(6):2116-22.

8. Atluri P, Goldstone AB, Fox J, Szeto WY, Hargrove WC. Port access cardiac operations can be safely performed with either endoaortic balloon or Chitwood clamp. Ann Thorac Surg. 2014;98(5):1579-83 discussion 1583-1574.

9. Barbero C, Marchetto G, Ricci D, El Qarra S, Attisani M, Filippini C, et al. Right Minithoracotomy for mitral valve surgery: impact of tailored strategies on early outcome. Ann Thorac Surg. 2016;102(6):1989-94.

10. van der Merwe J, Van Praet F, Vermeulen Y, Casselman F. Complications and pitfalls in minimally invasive atrioventricular valve surgery utilizing endo-aortic balloon occlusion technology. J Vis Surg. 2018;4:248.

11. De Praetere $H$, Verbrugghe $P$, Rega F, Meuris B, Herijgers P. Starting minimally invasive valve surgery using endoclamp technology: safety and results of a starting surgeon. Interact Cardiovasc Thorac Surg. 2015;20(3):351-8.

12. Malvindi PG, Margari V, Mastro F, Visicchio G, Kounakis G, Favale A, et al. External aortic cross-clamping and endoaortic balloon occlusion in minimally invasive mitral valve surgery. Ann Cardiothorac Surg. 2018;7(6):748-54.

13. Bentala M, Heuts S, Vos R, Maessen J, Scohy TV, Gerritse BM, et al. Comparing the endo-aortic balloon and the external aortic clamp in minimally invasive mitral valve surgery. Interact Cardiovasc Thorac Surg. 2015;21(3):359-65.

14. Dogan S, Aybek T, Risteski PS, Detho F, Rapp A, Wimmer-Greinecker G, et al. Minimally invasive port access versus conventional mitral valve surgery: prospective randomized study. Ann Thorac Surg. 2005;79(2):492-8.

15. Reichenspurner H, Detter C, Deuse T, Boehm DH, Treede H, Reichart B. Video and robotic-assisted minimally invasive mitral valve surgery: a comparison of the port-access and transthoracic clamp techniques. Ann Thorac Surg. 2005;79(2):485-90 discussion 490-481.

16. Modi P, Rodriguez E, Hargrove WC 3rd, Hassan A, Szeto WY, Chitwood WR Jr. Minimally invasive video-assisted mitral valve surgery: a 12-year, 2-center experience in 1178 patients. J Thorac Cardiovasc Surg. 2009;137(6):1481-7.

17. Aybek T, Dogan S, Wimmer-Greinecker G, Westphal K, Mortiz A. The micromitral operation comparing the port-access technique and the transthoracic clamp technique. J Card Surg. 2000;15(1):76-81.

18. Kowalewski M, Malvindi PG, Suwalski P, Raffa GM, Pawliszak W, Perlinski D, et al. Clinical safety and effectiveness of Endoaortic as compared to transthoracic clamp for small thoracotomy mitral valve surgery: metaanalysis of observational studies. Ann Thorac Surg. 2017;103(2):676-86.

19. Rival PM, Moore THM, McAleenan A, Hamilton H, Du Toit Z, Akowuah E, et al. Transthoracic clamp versus endoaortic balloon occlusion in minimally invasive mitral valve surgery: a systematic review and meta-analysis. Eur J Cardiothorac Surg. 2019;56(4):643-53.

20. Loforte A, Luzi G, Montalto A, Ranocchi F, Polizzi V, Sbaraglia F, et al. Videoassisted minimally invasive mitral valve surgery: external aortic clamp versus endoclamp techniques. Innovations (Phila). 2010;5(6):413-8.

21. Onnasch JF, Schneider F, Falk V, Mierzwa M, Bucerius J, Mohr FW. Five years of less invasive mitral valve surgery: from experimental to routine approach. Heart Surg Forum. 2002;5(2):132-5.

22. Agnino A, Albano G, Ruggieri VG, Roscitano C, Graniero A, Villari N, et al. Versatility of endoaortic balloon occlusion device for less invasive management of complex and reoperative cardiac cases. J Card Surg. 2019; 34(7):620-3.

\section{Publisher's Note}

Springer Nature remains neutral with regard to jurisdictional claims in published maps and institutional affiliations. 